\title{
RESEARCH AND INNOVATION AS DRIVERS OF SUSTAINABILITY AND COMPETITIVENESS OF THE BIOECONOMY: A COMPARATIVE ANALYSIS IN BIOEAST COUNTRIES
}

\begin{abstract}
Vlada VITUNSKIENĖ, Department of Applied Economics, Finance and Accounting, Faculty of Bioeconomy Development, Vytautas Magnus University, K. Donelaičio g. 58, LT-44248 Kaunas, Lithuania; vlada.vitunskiene@ vdu.lt (corresponding author)

Agnė DAPKUVIENÉ, Department of Applied Economics, Finance and Accounting, Faculty of Bioeconomy Development, Vytautas Magnus University, K. Donelaičio g. 58, LT-44248 Kaunas, Akademija, Lithuania; agne.dapkuviene@ vdu.lt

In the context of climate change, ecological boundaries, increasing environmental pressures and biodiversity loss, scientific community together with policy makers is searching for sources of change towards sustainable bioeconomy. Therefore, there is a clear scientific interest in connection of innovation and sustainable development as well as competitiveness. As RDI is proved by empirical research to be a driver of sustainability and competitiveness of bioeconomy, it is relevant to look at the innovation performance of different countries for comparison. This article aims to make a comparative overview of the bioeconomy related research and innovation performance between BIOEAST countries (Bulgaria, Czech Republic, Estonia, Croatia, Latvia, Lithuania, Hungary, Poland, Romania, Slovenia and Slovakia). Comparison to EU-27 (from 2020) and the EU Innovation Leaders is also made. The methodology is based on methods of analysis, interpretation and relevant comparisons of selected indicators. The research results point out that BIOEAST countries show very different innovation performance results. There is a wide innovation performance gap between most BIOEAST countries and the EU Innovation Leaders in terms of citable publications and especially patenting activity. Leading BIOEAST countries are in some cases similar to the EU Innovation Leaders. The research may be interesting for both researchers and policy makers and offers opportunities for future studies on the subject.
\end{abstract}

Keywords: research and innovation, BIOEAST countries, sustainability, competitiveness.

\section{INTRODUCTION}

In the context of climate change, expanding understanding of ecological boundaries, increasing environmental pressures and biodiversity loss, scientific community together with policy makers is in constant search of sources for the change towards sustainable bioeconomy. Naturally, there is a clear scientific interest in connection of innovation and sustainable development (Adenle et al., 2015; Llorca-Ponce et al., 2021). And empirical research has shown that research, development and innovation (RDI) helps achieving sustainable development (Adenle et al. 2013; Fankhauser et al., 2013; Adenle et al., 2015; Omri, 2019; Kuzma et al., 2020). Though Omri (2019) observed that technological innovation affects all the three pillars of sustainable development only in the rich countries whereas in middle-income countries it contributes to the economic and environmental pillars and no impact was found in low-income countries.

Importance of research and innovation for sustainable development is clearly stated in EU strategic documents. The European Green Deal stipulates that ,new technologies, sustainable solutions and disruptive innovation are critical to achieve the objectives of the European Green Deal“" (European Commission, 2019). European Commission's prepared Bioeconomy strategy's $(2012$, p. 2) goal "to pave the way to a more innovative, resource efficient and competitive society that reconciles food security with the sustainable use of renewable resources for industrial purposes, while ensuring environmental protection" that was confirmed to be still valid in the strategy's update in 2018, also echoes RDI importance for sustainable development. Horizon 2020 and the European Regional Development Fund, ensures ,important Research and Innovation outputs that can address cross-cutting challenges and opportunities in the bioeconomy" (European Commission, 2018, p. 7).

As seen above, the strategies also clearly state the innovation importance for competitiveness. This connection comes from broad scientific literature, where it is rather unanimously agreed that innovation is the main driver of long-term growth (following Solow's growth model) and competitiveness. This understanding has been also based on Schumpeter's creative destruction (Schumpeter, 1934) and the later developed process of creative accumulation (Pavitt, 1986; Granstrand et al., 1997; Cefis, Orsenigo, 2001). The latter model defines how firms have different capacity to accumulate technological capabilities and to generate innovation. "The accumulated technological competencies are the key determinants and drivers of firm innovation and competitiveness" (Dobrinsky, 2008, p. 53). Various empirical research can be found that confirms the impact of innovation performance on economic growth/competitiveness (Aghion, Howitt, 2008; Ciocanel, Pavelescu, 2015; Nekrep et al., 2018; Simionescu et al., 2021). According to the international reference standard for conceptualizing

Copyright (C) 2021 The Authors. Published by Vytautas Magnus University. This is an open-access article distributed under the terms of the Creative Commons Attribution License (CC BY 4.0), which permits unrestricted use, distribution, and reproduction in any medium, provided the original author and source are credited. 
and measuring innovation in the Oslo Manual (OECD/Eurostat, 2018), the research and development is a determining element in innovation process (Llorca-Ponce et al., 2021). Therefore, all three - research, development and innovation elements are important for competitiveness.

Since RDI is considered as a driver of sustainability and competitiveness of bioeconomy, it is of a scientific interest to look at the innovation performance of different countries for comparison. This article aims to make a comparative overview of the bioeconomy related research and innovation performance between BIOEAST countries. BIOEAST countries are involved in BIOEAST initiative ${ }^{1}$ and include eleven Central and Eastern European countries: Bulgaria, Czech Republic, Estonia, Croatia, Latvia, Lithuania, Hungary, Poland, Romania, Slovenia and Slovakia. According to European and Regional Innovation Scoreboard, most of BIOEAST countries are considered as moderate innovators with exception of Estonia that is categorized as strong innovator and Romania and Bulgaria that are modest innovators. None of BIOEAST countries are considered as Innovation Leaders, so it is important to see how far behind in RDI they are. BIOEAST countries are therefore compared to the EU Innovation Leaders such as Denmark, Finland, Sweden and the Netherlands (in 2018).

\section{RESEARCH METHODS}

For the comparative overview of bioeconomy related research and innovation performance in eleven BIOEAST countries, several indicators were analysed. The analysis mainly focusses on the bioeconomy related RDI outputs in BIOEAST countries as well as four EU Innovation Leaders (Sweden, Denmark, Finland and the Netherlands). Short comparisons to EU27 (from 2020) are also done. Two kinds of RDI outputs - patents, publications - are discussed. It also covers RDI input - EU funds allocation by bioeconomy related Horizon 2020 programmes in selected countries. As far as statistics allow, an overview of business RDI performance in different fully and partly bio-based industries is also made.

To sum up, the selected indicators are:

1) the patenting activities by bioeconomy related field of technology according to the patent applications per million inhabitants. Applications per Mio inhab. were calculated as a ratio of cumulative patent applications over 2015-2019 to million inhabitants at the last year of the period. Five years cumulative data were used for the analysis due to the fact that most countries applicated only a few patents per year (or none in a given year) for the separate technological fields in question.

2) citable publications by bioeconomy related research areas according to the citable publications per million inhabitants;

3) EU funds allocation by bioeconomy related Horizon 2020 programmes according to the share of net EU contribution.

4) Proportion of enterprises undertaking innovation activities of the main fully and partly bio-based industries of bioeconomy. The innovating enterprises with 10 or more employees are included in the analysis. In this article, fully bio-based industries are understood as a processing biomaterial to higher added value products (i.e. manufacture of food, beverages and tobacco, wood, paper and leather products). Meanwhile, the partly bio-based industries include the manufacture of bio-based products that are wholly or partly derived from biomaterials (i.e. manufacture of bio-based textile and apparel, chemicals, pharmaceuticals, rubber and plastics, furniture, bioenergy, etc.).

Data sources used:

- For patenting activities European Patent Office (EPO) and Eurostat data was used.

- For citable publications analysis data was extracted from the publicly available SJR - SCImago Journal \& Country Rank portal that includes the journals and country scientific indicators based on scientometric information provided by the Scopus database.

- For EU funds allocation by bioeconomy related Horizon 2020 programmes Horizon 2020 Country Profiles data in Research and innovation Statistics portal was used.

- For proportion of enterprises undertaking innovation activities of the main fully and partly bio-based industries in BIOEAST countries and the EU Innovation Leaders Community Innovation Survey in 2016-2018 (Eurostat) data was used.

\section{RESULTS}

Patents are a widely accepted measure of innovation performance (Archibugi, 1992; Raghupathi, Raghupathi, 2017; Kalapouti, 2020). Therefore, first of all, the patenting activity of BIOEAST countries was analysed. In general, the intensity of patenting activity was much lower in BIOEAST countries compared to all EU-27 with differences from 8 to 27 times in applications per million inhabitants. The share of pharmaceuticals, basic materials chemistry and food chemistry patents among all BIOEAST countries patents in 2015-2019 amounted to 6.6-4.5\%, whereas in EU-27 these figures were lower, what indicates that BIOEAST countries were relatively more focused on research and technologies development in these fields.

The cumulative patent applications data of 2015-2019 (Figure 1) shows that Slovenia is the leader among BIOEAST countries with total 71.1 patent applications per million inhabitants in identified bioeconomy related fields, followed by Czech Republic with 30.6 patents submitted for every million inhabitants and Estonia (third in this ranking with 23.4 patent applications per Mio inhab.). Slovakia, Romania and Bulgaria were at the lower end of the ranking with 6.4, 1.1 and 3.4 applications per

\footnotetext{
${ }^{1}$ A political Central-Eastern European Initiative for Knowledge-based Agriculture, Aquaculture and Forestry in the Bioeconomy, that offers a common political commitment and shared strategic research and innovation framework for working towards sustainable bioeconomies in the Central and Eastern European (CEE) countries.
} 
Mio inhabitants respectively. In comparison, the EU Innovation Leader countries had from 172 to 587 patent applications in identified bioeconomy fields per million inhabitants.

Looking deeper, the highest patenting activity in Slovenia is observed in organic fine chemistry field with 25 patents per million inhabitants, leaving behind Czech Republic (9.4 patents) and Hungary (4.8 patents) as well as Finland and Sweden with 12.3 and 22.5 patents per Mio inhab. respectively. Other patenting focal points in Slovenia are pharmaceuticals and biotechnology (12.5 and 12 patents per Mio inhab. respectively). Few other BIOEAST countries are somewhat on the similar level of patenting activity only in biotechnology field with 9.7 patents per million inhabitants in Lithuania and 9.1 patents per Mio inhab. in Estonia. Whereas Denmark had 216.8 patents per million inhabitants during 2015-2019. Patenting activities in other fields and other BIOEAST countries are of mostly negligible levels.

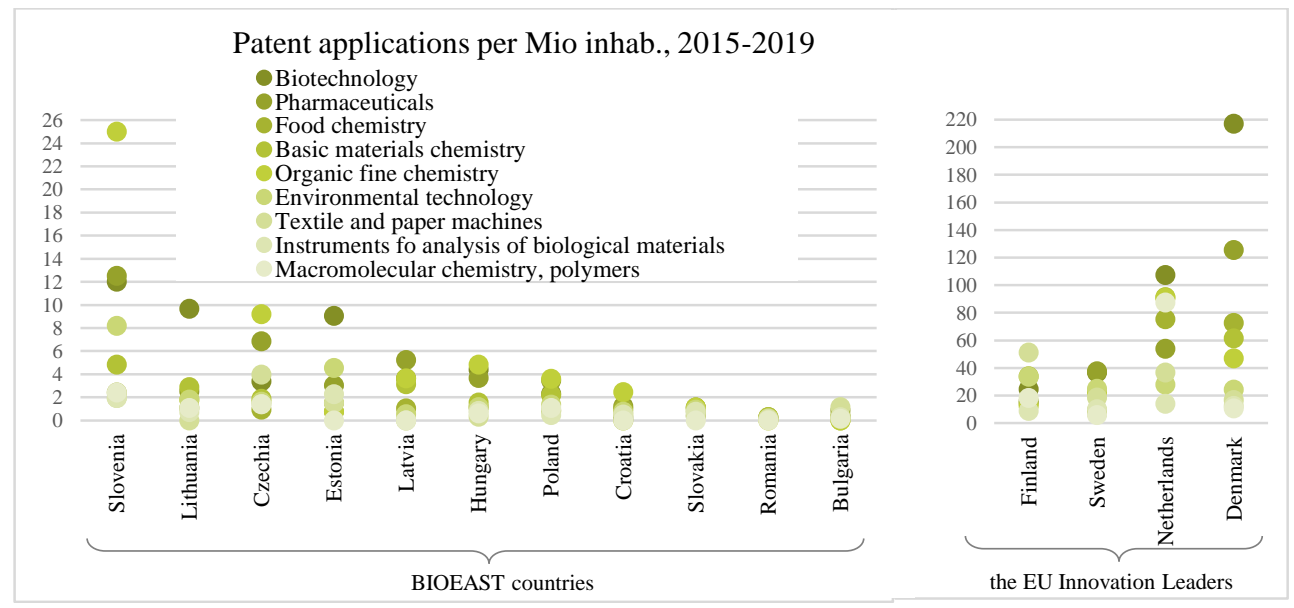

Source: own calculation based on the European Patent Office (EPO) and Eurostat data

Figure 1. Patenting activities by bioeconomy related field of technology in BIOEAST countries and in the EU Innovation Leaders, 2015-2019

Another important indicator of RDI activities is total number of citable scientific publications across bioeconomy related research areas such as life sciences, physical and health sciences. The total share of bioeconomy related citable publications prepared by BIOEAST and EU-27 researchers in 2019 was on a similar level of around 27-28\%. While BIOEAST countries showed a relative specialization in agriculture and biological sciences research areas the EU-27 was relatively more focused on biochemistry, genetic and molecular biology. Nonetheless, these two research areas were the largest among all bioeconomy related ones both in BIOEAST countries and EU-27. The citable scientific publications intensity (measured per Mio. inhabitants) was higher in EU-27 than in BIOEAST countries in all areas except for veterinary science.

An analysis of scientific citable publications data per million inhabitants demonstrated that again the leaders among BIOEAST countries are Estonia, Slovenia and Czech Republic (Figure 2) with totals of 888, 770 and 700 publications respectively (close to the Netherlands with 892 publications in total). They have also shown the highest performance in production of public-private co-publications (Slovenia 95.3, Czech Republic 60.2, Estonia 53 public-private co-publications per Mio. inhabitants). Though only Slovenia was above EU average (86.4 publications), which illustrates very weak academia-business links in BIOEAST countries compared to EU and EU Innovation Leaders. Worst results were delivered by Romania, Bulgaria and Lithuania with less than 20 public-private co-publications per million inhabitants in 2018.

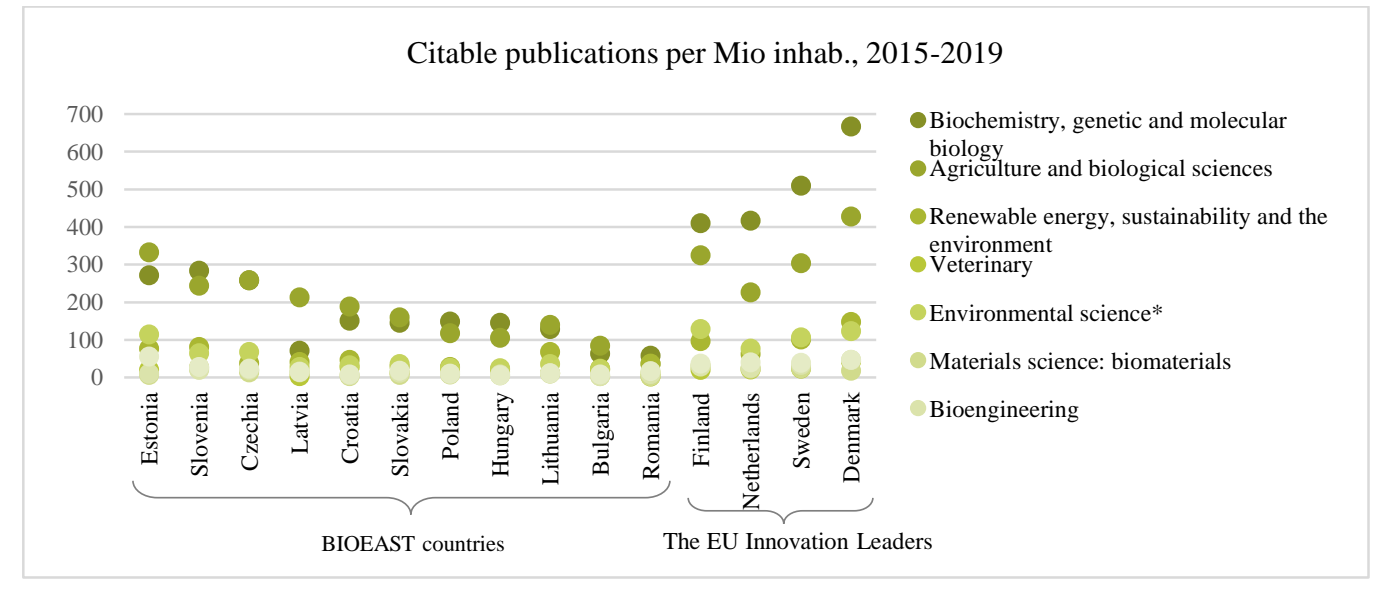

Source: own calculation based on the SJR — SCImago Journal \& Country Rank [Portal] and Eurostat data Note: *the following bioeconomy related science areas are included in the Environmental science categories: ecological modelling, ecology, nature and landscape conservation.

Figure 2. Citable publications by bioeconomy related research areas of BIOEAST countries and the EU Innovation Leaders, 2015-2019 
On the other hand, according to the data on top $10 \%$ most-cited scientific publications, Czech Republic is replaced by Lithuania in the top 3 of BIOEAST countries with score of 50.1 in $2018^{2}$ (Estonia and Slovenia had scored 81.1 and 73.4 respectively). While the worst in terms of high impact scientific publications was noticed in Romania, Croatia and Bulgaria (36.3, 26.8 and 20.9 scores respectively).

When looking at the various sciences areas, both agricultural and biological sciences, and biochemistry, genetics and molecular biology sciences amounted biggest share of publications in bioeconomy related research areas in all BIOEAST countries as well as in the EU Innovation leaders (Figure 2). Estonian scientists have published 332 publications in agricultural and biological sciences, surpassing all EU Innovation Leaders except Denmark (with 428 publications). Czech Republic is second among BIOEAST countries with 259 publications, Slovenia is third with 244. Only Bulgaria and Romania had less than 100 publications in the area. In biochemistry, genetics and molecular biology sciences highest number of publications was published in Slovenia (284), followed by Estonia and Czech Republic (271 and 259 publications respectively). Latvia, Bulgaria and Romania had the lowest number of publications in this area. While the EU Innovation Leaders had much higher numbers of publications in biochemistry, genetics and molecular biology sciences: from 410 in Finland to 667 in Denmark.

All other sciences areas had significantly lower numbers of publications, with similarly low quantities of publications in materials science (biomaterials), bioengineering and biomedical engineering in the EU Innovation Leaders and leading BIOEAST countries. Overall, most of BIOEAST countries, especially Latvia, Poland, Hungary, Bulgaria and Romania, shows very low performance in publications in bioeconomy related science areas compared to the EU Innovation Leaders.

As mentioned in second section, Horizon 2020 funding for bioeconomy related RDI projects was chosen for comparison among BIOEAST countries as an input of RDI. In BIOEAST countries, net EU contribution under Horizon 2020 amounted to EUR 2958.5 million., which accounted for 5.2\% of the total net EU contribution in the EU-27 during the 2014-2020. H2020 funds intensity per capita was more than three times lower in BIOEAST countries compared to EU27 (EUR 29 vs EUR 110 per capita) during the same period. Whereas the highest net EU contribution per capita was in Estonia and Slovenia while the rest of BIOEAST countries were far behind (Bulgaria, Poland and Romania were at the end of the rank). The highest total share of H2020 funds located to Bioeconomy related programmes were in Slovakia (31\%), Croatia (32.2\%) and Romania (29.4\%). In comparison to EU-27, relatively higher share of net EU contribution to bioeconomy related programmes was allocated in BIOEAST countries with highest difference in SC2 programme "Food security, sustainable agriculture and forestry, marine and maritime and inland water research and the bioeconomy" (7.4\% vs. 5\%). Among BIOEAST countries, the highest SC2 proportion was in Slovakia (21.5\%), followed by Romania (13.5\%), Latvia (9\%), Hungary (8.3\%), Estonia and Croatia (9\% each), indicating the strong specialization of R\&D activities in the field of SC2. On the other hand, the lowest shares were recorded in the Czech Republic (4.2\%), Poland (4.6\%) and Slovenia (6\%). EU Innovation leaders had similar shares of funds allocated to SC2 (Sweden 3.9\%, the Netherlands 5.6\%, Finland 5.8\% and Denmark 7.7\%).

Projects under Societal Challenge 3 "Secure, clean and efficient energy" were most funded in Croatia, Bulgaria and Slovenia $(17.2 \%, 17.2 \%$ and $13.8 \%$ of total EU contribution under H2020 respectively), surpassing the EU Innovation Leaders. In Societal Challenge 5 "Climate action, environment, resource efficiency and raw materials", Slovenia, Croatia and Romania have the highest shares, although they are rather low (6.5\%, 5.4\% and 5\% respectively). Though it should be noted that these two H2020 funding areas are only partly related to bioeconomy.

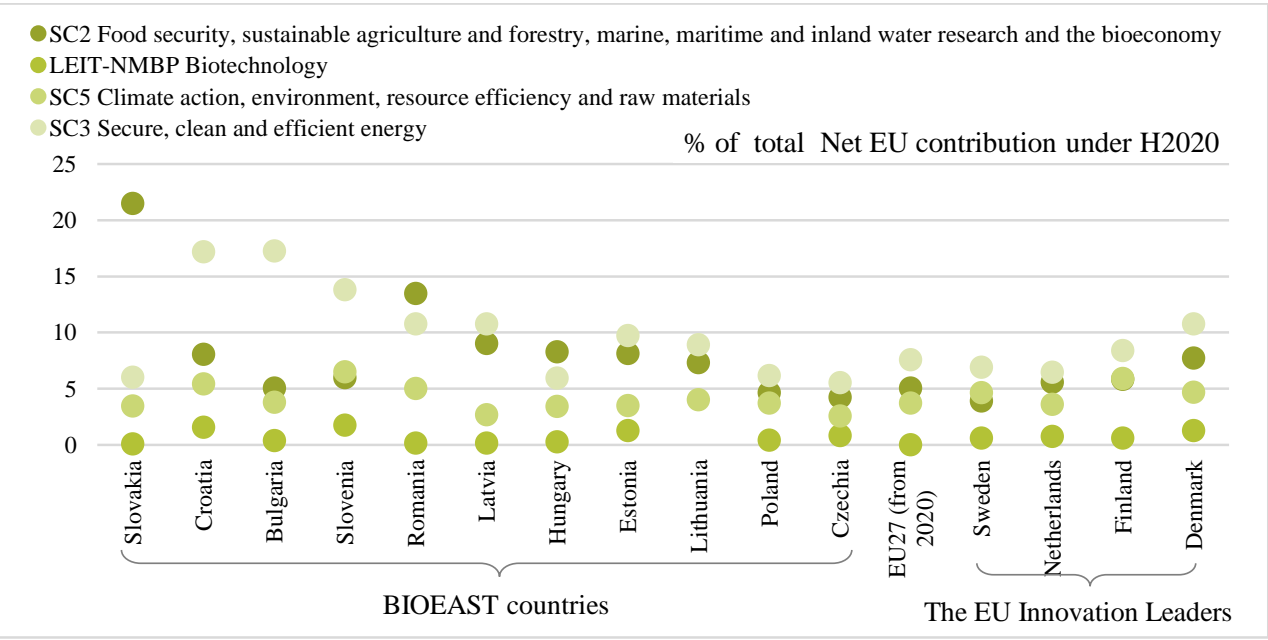

Source: own composition based on Research and innovation Statistics portal: Horizon 2020 Country Profiles

Figure 3. EU funds allocation by bioeconomy related Horizon 2020 programmes in BIOEAST countries and the EU Innovation Leaders, 2014-2020

\footnotetext{
${ }^{2} 10 \%$ most cited publications worldwide as $\%$ of total scientific publications of the country; data extracted from the European innovation scoreboard 2020 Database.
} 
The results of Community Innovation Survey (CIS) in 2018, presented in Figure 4, reveal several features of innovation activities in ten industries that were fully or partly included in the bioeconomy. In Estonia 100\% of enterprises in manufacture of pharmaceuticals were considered as innovative enterprises (which had either introduced an innovation or had any kind of innovative activity). The same situation is observed only in Finland when comparing BIOEAST countries and the EU Innovation Leaders. This industry has the highest share of innovative enterprises in most of the compared countries, together with manufacture of chemicals. Thus, in Hungary, Poland, Romania, Slovakia less than $50 \%$ of enterprises showed some form of innovation activity in latter sector. Romania and Slovakia had less than 50\% of innovative enterprises in manufacture of pharmaceuticals as well.

Other sectors like manufacture of food products and beverages, rubber and plastics, textiles, paper, wood products and furniture and in industries of sewerage, waste management, remediation as well as electricity and gas had less than $50 \%$ of innovating companies in most of BIOEAST countries. Nonetheless, leading BIOEAST countries in terms of ratio of innovative enterprises (Estonia, Croatia, Slovenia and Lithuania) had somewhat similar shares to those of the EU Innovation Leaders: Lithuania being similar to Sweden, Croatia and Slovenia to Denmark, Estonia to Finland. Other BIOEAST countries lag behind. It should be noted that Lithuania is the only BIOEAST country that has no industries where share of innovating enterprises is lower than $50 \%$.

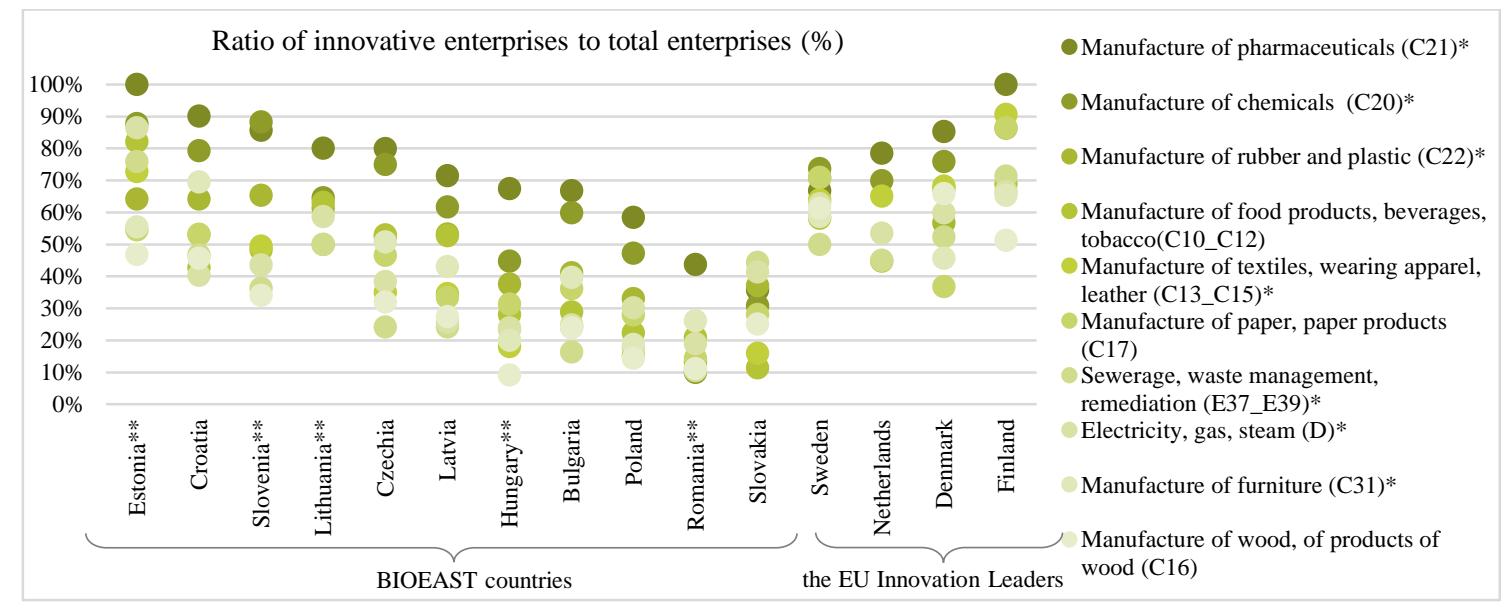

Source: own composition based on Eurostat data sources of the Community Innovation Survey (CIS, 2018)

Notes: *in partly bio-based industries, the data represent both the bio-based and the non-bio-based processing combined due to the limited availability of data needed for separate indicators; **data for majority industries in 2016-2018, for several others industries in 2014-2016.

Figure 4. Proportion of enterprises undertaking innovation activities of the main fully and partly bio-based industries in BIOEAST countries and the EU Innovation leaders, 2016-2018

\section{CONCLUSIONS}

Estonia justifies its attribution to strong innovators as the overview shows high results in citable scientific publications and highest ratio of innovative enterprises among BIOEAST countries. Slovenia being very close to Estonia's results and top among moderate innovators in BIOEAST countries.

Slovakia, Croatia and Bulgaria show rather paradoxical results of RDI inputs and outputs with relatively higher allocation of Horizon 2020 funds to bioeconomy related areas and providing mostly lowest results in patents and scientific publications. On the other hand, Estonia, Lithuania and Czech Republic had rather high RDI outputs, but allocated the lowest share of Horizon 2020 funds to bioeconomy related areas.

There is a wide innovation performance gap between most BIOEAST countries and the EU Innovation Leaders in terms of citable publications and especially patenting activity.

Despite differences in RDI output between BIOEAST countries and the EU Innovation Leaders, similar share of enterprises in Estonia, Croatia, Slovenia and Lithuania had either introduced an innovation or had any kind of innovative activity as in the EU Innovation Leader countries in main fully and partly bio-based industries.

Acknowledgement. The research was supported by the Horizon 2020 Programme project "BIOEASTsUP" under grant agreement No 862699 - BIOEASTsUP

\section{REFERENCES}

1. Archibugi, D. 1992. Patenting as an indicator of technological innovation: a review. Science and Public Policy, Vol. 19(6), pp. 357-368.

2. Adenle, A. A., Haslam, G. E., Lee, L. 2013. Global assessment of research and development for algae biofuel production and its potential role for sustainable development in developing countries. Energy Policy, Vol. 61, pp. $182-195$. https://doi.org/10.1016/j.enpol.2013.05.088

3. Adenle, A. A., Azadi, H., Arbiol, J. 2015. Global assessment of technological innovation for climate change adaptation and mitigation in developing world. Journal of Environmental Management, Vol. 161, pp. 261-275. https://doi.org/10.1016/j.jenvman.2015.05.040 
4. Aghion, P., Howitt, P. W. 2008. The economics of growth. MIT press.

5. Cefis, E., Orsenigo, L. 2001. The Persistence of Innovative Activities: A Cross-Countries and Cross-Sectors Comparative Analysis. Research Policy, Vol. 30(7), pp. 1139-1158. https://doi.org/10.1016/S0048-7333(00)00139-6

6. Ciocanel, A. B., Pavelescu, F. M. 2015. Innovation and competitiveness in European context. Procedia Economics and Finance, Vol. 32, pp. 728-737. https://doi.org/10.1016/S2212-5671(15)01455-0

7. Dobrinsky, R. 2008. Innovation as a key driver of competitiveness. UNECE Annual Report Economic Essays, Vol. 6, pp. 53-59.

8. European Commission. 2012. Innovating for Sustainable Growth: A Bioeconomy for Europe. COM(2012) 60 final.

9. European Commission. 2018. A sustainable bioeconomy for Europe: strengthening the connection between economy, society and the environment. Updated Bioeconomy Strategy. Directorate-General for Research and Innovation, European Commission.

10. European Commission. 2019. The European Green Deal. COM(2019)640 final.

11. European Parliament, 2010. The Lisbon Strategy 2000 - 2010, An analysis and evaluation of the methods used and results achieved, Directorate General for Internal Policies.

12. Fankhauser, S., Bowen, A., Calel, R., Dechezleprêtre, A., Grover, D., Rydge, J., Sato, M. 2013. Who will win the green race? In search of environmental competitiveness and innovation. Global Environmental Change, Vol. 23(5), pp. 902-913. https://doi.org/10.1016/j.gloenvcha.2013.05.007

13. Granstrand, O., Patel, P., Pavitt, K. 1997. MultiTechnology Corporations: Why They Have 'Distributed' rather than 'Distinctive Core' Competencies. California Management Review, Vol. 39(4), pp. 8-25. https://doi.org/10.2307/41165908

14. Kalapouti, K., Petridis, K., Malesios, C., Dey, P. K. 2020. Measuring efficiency of innovation using combined Data Envelopment Analysis and Structural Equation Modeling: empirical study in EU regions. Annals of Operations Research, Vol. 294(1), pp. 297-320. https://doi.org/10.1007/s10479-017-2728-4

15. Kuzma, E., Padilha, L. S., Sehnem, S., Julkovski, D. J., Roman, D. J. 2020. The relationship between innovation and sustainability: A meta-analytic study. Journal of Cleaner Production, Vol. 259, 120745, pp. 1-10. https://doi.org/10.1016/j.jclepro.2020.120745

16. Llorca-Ponce, A., Rius-Sorolla, G., Ferreiro-Seoane, F. J. 2021. Is Innovation a Driver of Sustainability? An Analysis from a Spanish Region. Sustainability, Vol. 13(16), 9286, pp. 1-31. https://doi.org/10.3390/su13169286

17. Nekrep, A., Strašek, S., Boršič, D. 2018. Productivity and Economic Growth in the European Union: Impact of Investment in Research and Development. Naše gospodarstvo/Our Economy, Vol. 64(1), pp. 18-27. https://doi.org/10.2478/ngoe-2018-0003

18. OECD/Eurostat. 2018. Oslo Manual 2018.The Measurement of Scientific, Technological and Innovation Activities. OECD, Paris, France.

19. Omri, A. 2020. Technological innovation and sustainable development: Does the stage of development matter? Environmental Impact Assessment Review, Vol. 83, 106398, pp. 1-10. https://doi.org/10.1016/j.eiar.2020.106398

20. Pavitt, K. 1986. 'Chips' and 'Trajectories': How Does the Semiconductor Influence the Sources and Directions of Technical Change? in: R. MacLeod (ed.), Technology and the Human Prospect, London: Frances Pinter, pp. 31-54.

21. Raghupathi, V., Raghupathi, W. 2017. Innovation at country-level: association between economic development and patents. Journal of Innovation and Entrepreneurship, Vol. 6(1), pp. 1-20. https://doi.org/10.1186/s13731-017-0065-0

22. Schumpeter, J.A. 1934. The Theory of Economic Development; Harvard University Press: Cambridge, MA, USA.

23. Simionescu, M., Pelinescu, E., Khouri, S., Bilan, S. 2021. The Main Drivers of Competitiveness in the EU-28 Countries. Journal of Competitiveness, Vol. 13(1), pp. 129-145. https://doi.org/10.7441/joc.2021.01.08 